una combinación de anticuerpos. La mayoría de los autores señala que la expresión de CD99 es típica del PNET, como sucedió en nuestro caso. Sin embargo, el diagnóstico diferencial entre el PNETy el sarcoma extraóseo de Ewing obliga a otras tinciones, ya que ambos tumores marcan positivo para CD99. Se deben utilizar entonces para excluir el sarcoma de Ewing marcadores neuronales como enolasa específica neuronal, que es positiva en el PNET y negativa en el sarcoma de Ewing 5 .7.

La evolución del PNET renal depende básicamente del estadio al diagnóstico, la extensión de la resección quirúrgica, la existencia de márgenes, la clasificación histológica y el tiempo hasta la adyuvancia. El PNET es un tumor agresivo que tiende a recurrir localmente y a metastatizar a los ganglios linfáticos, el pulmón, el hígado, el hueso y la médula ósea, condicionando un peor pronóstico ${ }^{8}$. La tasa de supervivencia libre de enfermedad a los cinco años para todos los estadios es de un $45-55 \%{ }^{3}$. Los pacientes con enfermedad diseminada al diagnóstico tienen una supervivencia media de solo dos años ${ }^{3}$. La poliquimioterapia, sobre la base de altas dosis de vincristina, adriamicina y ciclofosfamida, ha demostrado buenos resultados ${ }^{3,8}$. Sin embargo, no se han publicado estudios randomizados sobre la efectividad de diferentes regímenes de quimioterapia debido a lo excepcional del tumor ${ }^{3}$.

A modo de conclusión, podríamos decir que los PNET de origen renal son una entidad poco frecuente y se caracterizan por su agresividad y su alta capacidad de recurrencia local y a distancia, lo cual ensombrece el pronóstico. Esta entidad se debe considerar en el diagnóstico diferencial de las masas renales en pacientes jóvenes, en particular en aquellos casos en que se presentan como enfermedad diseminada de inicio. El diagnóstico es por exclusión de otros tumores renales de célula pequeña. Determinar el diagnóstico anatomopatológico exacto tiene una gran importancia clínica, ya que puede condicionar la utilización de diferentes regímenes de quimioterapia que puedan conseguir un mejor control de la enfermedad.

\section{B I B L I O G R A F Í A}

1. Stout AP. A tumour of the ulnar nerve. Proc of the NY Pathol Soc. 1918;18:2-12.

2. Weeks DA, Beckwith JB, Mierau GW, Zuppan CW. Renal neoplasm mimicking rhabdoid tumor of the kidney. A report from the national Wilms' Tumor Study Phatology Center. Am J Surg Pathol. 1991;15:1042-54.

3. Casella R, Moch H, Rochlitz C, Meier V, Seifert B, Mihatsch MJ, et al. Metastasic primitive neuroectodermal tumor of the kidney in adults. Eur Urol. 2001;39:613-7.

4. Cuesta Alcalá JA, Solchaga Martínez A, Caballero Martínez MC, Gómez Dorronsoro M, Pascual Piedróla I, Ripa Saldías L, et al. Tumor neuroectodérmico primitivo renal (PNET): 26 casos. Estado actual de su diagnóstico y tratamiento. Arch Esp Urol. 2001;54:1081-93.

5. Rodríguez-Galindo C, Marina NM, Fletcher BD, Parham DM, Bodner SM, Meyer WH. Is primitive neuroectodermal tumor of the kidney a distinct entity? Cancer. 1997;79:2243-50.

6. Friedrichs N, Vorreuther R, Poremba C, Schafer KL, Böcking A, Buettner R, et al. Primitive neuroectodermal tumor (PNET) in the differential diagnosis of malignant kidney tumors. Phatol Res Prac. 2002;198:563-9.

7. Premalata CS, Gayathri DV, Biswas S, MuKherjee G, Balu S, Sundareshan TS, et al. Primitive neuroectodermal tumor of the kidney. A report of two cases diagnosed by fine needle aspiration cytology. Acta Cytol. 2003;47:475-9.

8. Kushner BH, Hadju SI, Gulati SC, Erlandson RA, Excelby PR, Lieberman PH. Extracranial primitive neuroectodermal tumors. The Memorial Sloan-Kettering Cancer Center experience. Cancer. 1991;67:1825-9.

F. Cabrera-Meirás*, G. Duque-Ruiz, V.M. Martínez-Silva y

O. Leiva-Galvis

Servicio de Urología, Hospital Universitario 12 Octubre, Madrid, España

Autor para correspondencia.

Correo electrónico: cabdoc@hotmail.com (F. Cabrera-Meirás).

\title{
Tumor de celulas de sertoli esclerosante. Un subtipo infrecuente de neoplasia testicular
}

\section{Sclerosing sertoli cell tumor. An unfrequent type of testicular neoplasm}

\section{Sr. Director:}

Las neoplasias de los cordones sexuales del estroma testicular o tumores no germinales representan aproximadamente $5 \%$ de los tumores testiculares, siendo en su mayoría tumores de células de Leydig $^{1}$. Los tumores testiculares puros de células de Sértoli son muy infrecuentes y representan cerca del $1 \%$ de los tumores testiculares ${ }^{2}$. Considerados habitualmente benignos, son una entidad heterogénea debido a la variabilidad histológica y a las diferencias en sus manifestaciones clínicas. Se clasifican según sus características histológicas en los subtipos: clásico (no especificado), de células grandes calcificadas y esclerosante ${ }^{3}$.

Presentamos el caso de un paciente varón de 30 años de edad con antecedentes de cólicos nefríticos y sinusitis que consultó por presentar discreto aumento de volumen de testículo izquierdo asociado a dolor testicular. A la exploración se evidenció testículo izquierdo doloroso a la palpación con predominio en cola de epidídimo sin tumoraciones. Se practicó ecografía testicular (fig. 1) donde se detectó nódulo hipoecoico de $11 \mathrm{~mm}$ con sombra acústica posterior e incremento de la irrigación sanguínea, sugestivo de 


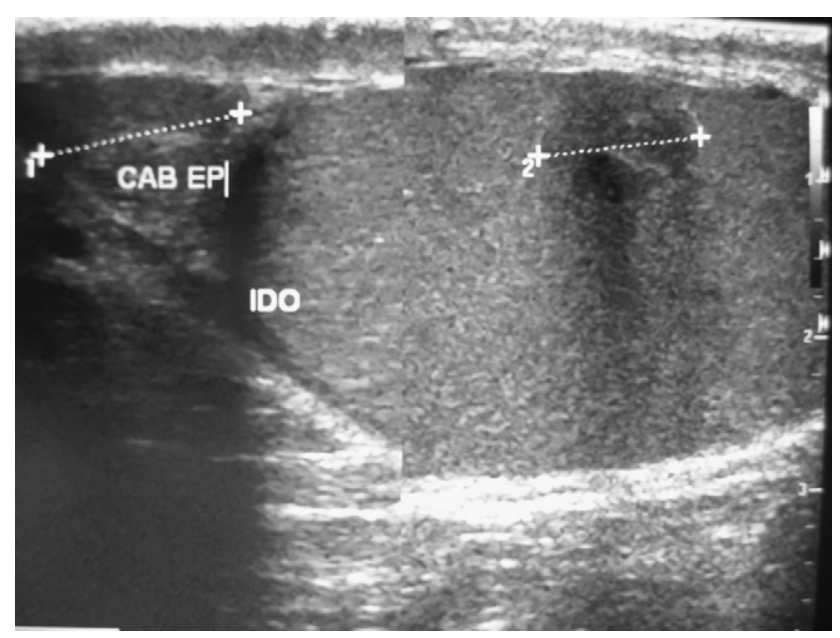

Figura 1 - Ecografía testicular donde se aprecia nódulo hipoecoico de bordes regulares con sombra acústica posterior.

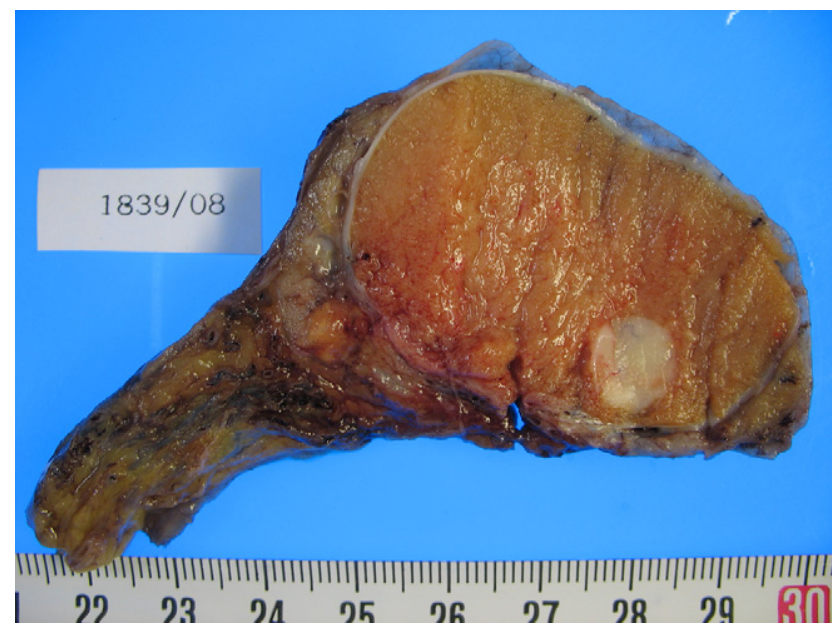

Figura 2 - Pieza quirúrgica con nódulo bien delimitado, blanquecinogrisáceo de $11 \mathrm{~mm}$ en su diámetro mayor.

neoformación testicular. Los marcadores tumorales séricos: $\alpha$-fetoproteína, $\beta$-HCG y LDH fueron normales y en TAC no se detectaron adenopatías pélvicas ni retroperitoneales.

Se procedió a practicar bajo anestesia general orquiectomía inguinal izquierda. El estudio histopatológico macroscópico evidenció el testículo izquierdo de $5,5 \times 3,5 \mathrm{~cm}$., observándose a nivel del polo inferior un nódulo bien delimitado, blanquecino grisáceo de $11 \mathrm{~mm}$ en su diámetro mayor y de consistencia elástica (fig. 2). El análisis microscópico demostró un nódulo bien delimitado, no encapsulado, que estaba formado por una proliferación de elementos cordonales y en menor cantidad tubulares, inmersos en estroma densamente esclerosado. Las células eran pequeñas con citoplasma claro, no se observaron mitosis y la tumoración era intratesticular en toda su extensión. Entre las técnicas de inmuno histoquímica practicadas se observó expresividad con enolasa neuronoespecifica y la vimentina diagnosticándose un tumor de células de Sértoli esclerosante. El paciente actualmente vive libre de enfermedad y permanece en control.

Los tumores primarios de testículo están originados en el $95 \%$ de los casos por células germinales y solo $5 \%$ lo constituyen células de los cordones sexuales del estroma testicular. Los tumores del estroma se clasifican en los de células de Leydig, células de Sértoli, células Sértoli-Leydig, tumores de la granulosa y los mixtos ${ }^{4,5}$. Los de las células de Sértoli son extremadamente infrecuentes y representan menos de $1 \%$ de todos los tumores testiculares. Contienen células de Sértoli que se organizan en túbulos, cordones o agregados irregulares. Según su histología se clasifican en 3 subtipos: clásico, el de células grandes calcificadas y el esclerosante ${ }^{3}$. Este último descrito por Zukerberg y colaboradores en su revisión de aproximadamente 200 casos de tumores de los cordones sexuales del estroma testicular; en su serie la variedad esclerosante se observó en 10 casos con características histológicas y clínicas similares ${ }^{6}$. La variedad esclerosante se distingue por presentar hipocelularidad con un estroma esclerótico difuso y ausencia tanto de necrosis como de invasión vascular o linfática. Habitualmente son tumores asintomáticos pequeños entre $0,5-2 \mathrm{~cm}$ y excepcionalmente miden más de $5 \mathrm{~cm}$ en su diámetro mayor, bien delimitados, de color blanco o gris y con una superficie sólida al corte. Aunque pueden presentarse en cualquier edad tienen un pico de incidencia entre los 35-50 años ${ }^{5}$. A diferencia de la variedad de células grandes calcificantes que se ha descrito asociado a bilateralidad y multifocalidad, la variedad esclerosante es unilateral afectando a ambos testículos por igual. Otra diferencia entre ambos subtipos es que solo el tumor de células grandes calcificantes se asocia a Síndrome de Peutz-Jeghers y al Complejo de Carney (tumores mixoides de piel, mama y corazón) ${ }^{7}$. De forma general aproximadamente $25 \%$ los tumores de células de Sértoli se asocian a actividad hormonal productora de estrógenos manifestándose en forma de ginecomastia ${ }^{8}$, esta característica esta ausente en la variedad esclerosante. Actualmente se considera que en la ausencia de signos radiológicos de extensión a ganglios linfáticos o metástasis a distancia la orquiectomía radical es el tratamiento aconsejado. Aunque habitualmente tienen un comportamiento benigno se aconseja la vigilancia de larga duración ya que hay pocos casos registrados en la literatura y hay casos aislados descritos con características histológicas que sugieren un comportamiento clínico más agresivo.

B I B L I O G R A F Í A

1. Kim I, Young RH, Scully RE. Leydig cell tumors of the testis. A clinicopathological analysis of 40 cases and review of the literature. Am J Surg Pathol. 1985;9:177-92.

2. Abell MR, Holtz F. Testicular and paratesticular neoplasms in patients 60 years of age and older. Cancer. 1968;21:852-70.

3. Giglio M, Medica M, de Rose AF, Germinale F, Ravetti JL, Carmignani G. Testicular sertoli cell tumours and relative subtypes. Analysis of clinical and prognostic features. Urol Int. 2003;70:205-10.

4. Mostofi FK, Theiss EA, Asheley DJB. Tumors of specialized gonadal stroma in human male subjects. Cancer. 1959;12:944. 
5. Young RH, Koelliker DD, Scully RE. Sertoli cell tumors of the testis, not otherwise specified. A clinicopathologic analysis of 60 cases. Am J Surg Path. 1998;22:709-21.

6. Zukerberg LR, Young RH, Scully RE. Sclerosing Sertoli Cell Tumor of the Testis. A Report of 10 cases. Am J Surg Pathol. 1991;15:829-34.

7. Carney JA, Gordon H, Carpenter PC, Shenoy BV, Go VLW. The complex of myxomas, spotty pigmentation and endocrine overactivity. Medicine. 1985;64:270-83.

8. Gabrilove JL, Freiberg EK, Leiter E, Nicolis GL. Feminizing and nonfeminizing Sertoli cell tumors. J Urol. 1980;124:757-67.
C.J. Yánez Benítez ${ }^{\mathrm{a}, *}$, C. Valero Valdivieso ${ }^{\mathrm{a}}$, J.I. Sanz Vélez ${ }^{b}$ y M. Marigil Gómez ${ }^{\mathrm{c}}$

${ }^{a}$ Servicio de Cirugía General y del Aparato Digestivo, Hospital San Jorge, Huesca, España

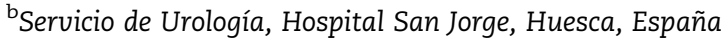

'Servicio de Anatomía Patológica, Hospital San Jorge, Huesca, España

*Autor para correspondencia.

Correo electrónico: carlosyb1@gmail.com (C.J. Yánez Benítez).

\title{
Pólipo fibroepitelial ureteral gigante resuelto con resección y sustitución intestinal
}

\author{
Giant fibroepithelial polyp of the ureter: treatment with ureteral \\ resection and intestinal substitution
}

\section{Sr. Director:}

Los pólipos fibroepiteliales del uréter son raros tumores mesenquimales. El primer caso fue descrito por Boross en 19291. Debido a su naturaleza benigna la mayoría de los autores recomiendan cirugía conservadora con técnicas mínimamente invasivas aunque en ocasiones debido al tamaño y localización del pólipo es necesario recurrir a la cirugía abierta.

Presentamos el caso de una mujer de 42 años sin antecedentes de interés que sufre cuadro de cólico renal izquierdo. En ecografía se aprecia hidronefrosis izquierda sin identificar la causa. La urografía intravenosa (fig. 1) revela retraso funcional de riñón izquierdo y ureterohidronefrosis severa hasta uréter ilíaco con numerosos pliegues. El TAC y la $\mathrm{RM}$ informan de un posible tumor en uréter izquierdo. La práctica de una ureteroscopia no fue concluyente por grandes dificultades de interpretación de los hallazgos tomándose biopsia de mucosa ureteral que demostró un urotelio normal con ligero edema e inflamación del corion subyacente. La citología urinaria fue negativa.

Se decide practicar exploración quirúrgica mediante laparotomía media en la que se muestra el uréter izquierdo ocupado por una tumoración de consistencia blanda de varios centímetros de grosor desde el cruce de los vasos ilíacos hasta el uréter yuxtapiélico (fig. 2), por lo que se decidió resecar todo el segmento ureteral afectado enviándolo para evaluación anatomopatológica intraoperatoria para decidir actitud sobre la unidad renal.

El informe intraoperatorio fue de pólipo fibroepitelial por lo que para conservar el riñón se decidió utilizar segmento ileal de sustitución. El estudio anatomopatológico definitivo confirma el diagnóstico de pólipo fibroepitelial ureteral.

La urografía intravenosa de control a los dos meses evidencia una mejoría de la dilatación y de la función del sistema excretor izquierdo, estando la paciente asintomática.
Los tumores del uréter no son frecuentes y representan menos del $1 \%$ de todos los tumores genitourinarios. Sólo el $20 \%$ de ellos son benignos y el pólipo fibroepitelial es el más frecuente ${ }^{2}$. Los tumores ureterales benignos pueden ser epiteliales o no epiteliales, originándose estos últimos a partir de elementos mesodérmicos de la pared ureteral y pueden corresponder a leiomiomas, fibroepiteliomas, linfangiomas, neurofibromas, hemangiomas, endometriomas, fibromas y pólipos fibroepiteliales ${ }^{1}$.

Generalmente tienen un origen congénito o inflamatorio aunque su etiología no ha quedado bien establecida. La mayoría son pólipos pequeños aunque también se han descrito lesiones de gran tamaño. A menudo son pólipos únicos aunque en ocasiones pueden ser múltiples.

Macroscópicamente se tratan de proyecciones filiformes que van desde pocos milímetros hasta poder alcanzar varios centímetros. En el estudio anatomopatológico se identifican como un grueso tallo fibroso con numerosos canales vasculares cubiertos por una capa de epitelio transicional normal o hiperplásico ${ }^{3}$.

Aunque pueden aparecer en cualquier etapa de la vida lo habitual es que afecten a adultos entre la tercera y quinta década de la vida y con predominio en el sexo masculino ${ }^{1}$. Son más frecuentes en el lado izquierdo y se pueden localizar en cualquier punto del uréter aunque predominan en el tercio superior.

La sintomatología consiste en dolor en el flanco o abdominal, infección del tracto urinario y macro microhematuria, sufriendo nuestra paciente dolor por uropatía obstructiva.

Las técnicas radiológicas no permiten distinguirlos de los tumores malignos de células transicionales y en ocasiones pueden dar falsos positivos en la citología urinaria ${ }^{4}$, no ocurrió así en nuestro caso, por lo que históricamente muchos pacientes eran sometidos innecesariamente a nefroureterectomías ${ }^{5}$. Por tanto la ureteroscopia con biopsia se considera el mejor procedimiento para el diagnóstico ${ }^{6}$, aunque en el caso clínico presentado no fuera concluyente. 